\title{
Peroxisome Proliferator-Activated Receptor Alpha Is Crucial for Iloprost-Induced in vivo Angiogenesis and Vascular Endothelial Growth Factor Upregulation
}

\author{
Federico Biscetti ${ }^{a}$ Eleonora Gaetani ${ }^{a}$ Andrea Flex ${ }^{a}$ Giuseppe Straface ${ }^{a}$ \\ Giovanni Pecorini $^{a} \quad$ Flavia Angelini $^{a}$ Egidio Stigliano $^{\mathrm{b}}$ Tamar Aprahamian $^{d}$ \\ Roy C. Smith ${ }^{\mathrm{e}}$ John J. Castellot ${ }^{\mathrm{e}}$ Roberto Pola ${ }^{\mathrm{a}, \mathrm{c}, \mathrm{e}}$ \\ a Laboratory of Vascular Biology and Genetics, Department of Medicine, A. Gemelli University Hospital and \\ ${ }^{b}$ Department of Pathology, Catholic University School of Medicine, Rome, and CIRCCS OASI, Troina, Italy; \\ ${ }^{\mathrm{d}}$ Molecular Cardiology, Boston University School of Medicine, and e Department of Anatomy and Cell Biology, \\ Tufts University School of Medicine, Boston, Mass., USA
}

\section{Key Words}

lloprost $\cdot$ Prostacyclin $\cdot$ Peroxisome proliferator-activated receptor- $\alpha \cdot$ Angiogenesis $\cdot$ Vascular endothelial growth factor

\begin{abstract}
We have previously demonstrated that iloprost, a stable prostacyclin $\left(\mathrm{PGI}_{2}\right)$ analogue, induces angiogenesis in vivo, through a vascular endothelial growth factor (VEGF)-dependent mechanism. In this study, we demonstrate that iloprostinduced angiogenesis and VEGF upregulation are modulated by peroxisome proliferator-activated receptor- $\alpha$ (PPAR $\alpha$ ), a ligand-inducible transcription factor that belongs to the nuclear hormone receptor superfamily and plays multiple biological activities in the vascular system. We show that iloprost is unable to induce angiogenesis in mice lacking the PPAR $\alpha$ gene (PPAR $\alpha-/-$ mice). Likewise, iloprost-induced VEGF upregulation is absent in PPAR $\alpha-/$ - mice. In contrast, iloprost induces a robust angiogenic response in wild-type mice, along with local upregulation of VEGF. Importantly, mice lacking the PPAR $\alpha$ gene exhibit a normal angiogenic response to VEGF, indicating that the absence of PPAR $\alpha$ does
\end{abstract}

not result in a general impairment of angiogenesis, but specifically affects the ability of iloprost to induce angiogenesis. Our data demonstrate unexpected functional relationships between the $\mathrm{PGI}_{2}$ system and the PPAR signaling pathway and shed new light on the molecular mechanisms involved in iloprost-induced angiogenesis.

Copyright $\odot 2008$ S. Karger AG, Basel

\section{Introduction}

Iloprost is a stable prostacyclin $\left(\mathrm{PGI}_{2}\right)$ analogue with proven efficacy for the treatment of several pathologic vascular conditions, such as pulmonary hypertension, Raynaud's phenomenon, and critical limb ischemia [1-3]. The beneficial effects of iloprost have always been attributed to its vasodilating and antiplatelet properties. However, we have recently demonstrated that, in addition to these well-characterized effects, iloprost is also able to induce angiogenesis in vivo, through upregulation of vascular endothelial growth factor (VEGF), a prototypical angiogenic cytokine with multiple biological activities in the vascular system [4].

\section{KARGER}

Fax +41613061234 E-Mail karger@karger.ch www.karger.com (c) 2008 S. Karger AG, Basel

1018-1172/09/0462-0103\$26.00/0

Accessible online at:

www.karger.com/jvr
Dr. Roberto Pola

Department of Anatomy and Cell Biology

Tufts University School of Medicine

136 Harrison Avenue, Boston, MA 02111 (USA)

Tel. +1 617636 0303, Fax +1 617636 6536, E-Mail roberto.pola@tufts.edu 
Iloprost classical pathway uses a G protein-coupled cell surface receptor named IP, whose activation leads to increased production of intracellular cAMP and consequent activation of the protein kinase A cascade, or calcium mobilization via phospholipase $\mathrm{C}$ activation [5]. In addition to this classical pathway, iloprost also utilizes peroxisome proliferator-activated receptors (PPARs), which are ligand-inducible transcription factors that belong to the nuclear hormone receptor superfamily [6]. In mammals, the PPAR family consists of three subtypes of proteins encoded by separate genes: PPAR $\alpha$, PPAR $\gamma$, and PPARס [7]. They act as heterodimers with the retinoid X receptor and regulate gene transcription by binding to specific response elements in the promoter of the target genes. In the present study, we evaluated whether PPAR $\alpha$ is important in the regulation of the angiogenic properties of iloprost.

\section{Materials and Methods}

\section{Mice}

Male PPAR $\alpha-/$ - mice (Pparatm1Gonz homozygous mice) and their wild-type littermates (129SV background; Jackson Laboratories) were used for all the experiments. Mice were 8-12 weeks old at the time of the experiments.

\section{Mouse Corneal Angiogenesis Assay}

Mice were anesthetized with an intramuscular injection of ketamine. A single corneal pocket was created by using a modified van Graefe cataract knife about $1.0 \mathrm{~mm}$ from the corneal limbus. Pellets containing $0.3 \mu \mathrm{g}$ of iloprost, VEGF, or control buffer were prepared and placed in each corneal pocket, as previously described [4]. Mice were sacrificed 6 days later with an overdose of ketamine. Eight to ten eyes were studied in each group. The investigation was approved by the local Ethics Committee.

\section{Quantification of Corneal Angiogenesis}

Corneal angiogenesis was quantified as established and described in previous reports [4]. Briefly, vessel length, circumferential extent of neovascularity, number of vessels per cross section, and lumen diameter were evaluated by using fluorescence microscopy. For this analysis, mice received an intracardiac injection of $500 \mu \mathrm{g}$ of the endothelial cell marker BS-1 lectin, conjugated with FITC (Vector Laboratories). Thirty minutes later, mice were sacrificed and each eye was enucleated and fixed in $1 \%$ paraformaldehyde solution for $1 \mathrm{~h}$. Corneal hemispheres were prepared under the dissecting microscope, placed on glass slides, and analyzed by using a fluorescent microscope. All quantifications were performed in a blinded fashion, by two independent operators.

\section{VEGF Immunohistochemistry}

For immunohistochemical staining, mice did not receive BS-1 lectin injection. Instead, they were sacrificed 6 days after pellet implantation and eyes were excised and fixed in $1 \%$ paraformal- dehyde solution for $1 \mathrm{~h}$. After fixation, corneas were embedded in paraffin and cut in cross sections. VEGF immunostaining was performed using a rabbit polyclonal anti-mouse VEGF antibody (Santa Cruz Biotechnology) followed by a biotinylated goat antirabbit immunoglobulin secondary antibody (Signet Labs), as previously described [4]. Negative control slides were prepared by substituting preimmune rat serum.

\section{Competitive RT-PCR}

For this set of experiments, the right corneas were implanted with pellets containing iloprost, while the left corneas of the same animals were implanted with pellets containing control buffer and served as internal control. Four days after surgery, corneas were harvested and RNA was extracted. Complementary DNA was obtained and amplified using the SuperScript preamplification system (Gibco-BRL, Paisley, UK). Signals were normalized to $18 \mathrm{~s}$ rRNA using optimal $18 \mathrm{~S}$ primer/competimer ratios as determined for the target gene following the manufacturer's recommendations (Ambion, Austin, Tex., USA). Primer sequences and PCR conditions were as previously described [4]. Results were expressed as mRNA fold increase, calculated as the ratio between VEGF mRNA expression in the right and left (control) corneas.

\section{ELISA}

Corneas treated with iloprost and control buffer were harvested 6 days after pellet implantation. VEGF165 levels were measured by ELISA (R\&D Systems, Minneapolis, Minn., USA). Results were expressed as protein fold increase, calculated as the ratio between VEGF protein levels in the right and left (control) corneas.

\section{In vivo Inhibition of VEGF Activity}

Activity of VEGF was systemically blocked in mice by transfecting the thigh muscles with a plasmid DNA encoding a soluble form of the murine VEGF receptor Flt-1, as previously described [4]. The plasmid was kindly provided by Dr. Kensuke Egashira. Soluble Flt-1 (sFlt-1) can suppress VEGF activity both by sequestering VEGF and by functioning as a dominant-negative inhibitor of VEGF receptors $[4,8]$. Control mice received an equal amount of empty plasmid with an intramuscular injection on the same time schedule. Eight eyes were analyzed in each group.

\section{Statistical Analysis}

All results are expressed as mean \pm SEM. Differences were analyzed by Student's t test and considered statistically significant at $\mathrm{p}<0.05$.

\section{Results}

Pellets containing iloprost were unable to induce corneal angiogenesis in PPAR $\alpha-/-$ mice (fig. 1a). The same pellets induced a robust angiogenic response in the corneas of their wild-type littermates (fig. 1b). Pellets containing VEGF induced angiogenesis in both PPAR $\alpha-/-$ and wild-type mice (fig. 1c, d). No angiogenic growth was 
Fig. 1. Impaired iloprost-induced angiogenesis in PPAR $\alpha-/-$ mice. a BS-1 lectin fluorescent staining showing iloprost-induced corneal angiogenesis in wild-type mice. b Iloprost is unable to induce angiogenesis in PPAR $\alpha-/-$ mice. $\mathbf{c}, \mathbf{d}$ PPAR $\alpha-/-$ and their wild-type littermates exhibit a proper angiogenic response to VEGF stimulation.

Fig. 2. Quantification of corneal angiogenesis. VEGF-induced angiogenesis is statistically similar, in terms of vessel length (a), lumen diameter (b), circumferential extent of neovascularity (c), and number of vessels (d) in PPAR $\alpha-/-$ mice and $129 \mathrm{SV}$ wild-type mice. a-d Iloprostinduced angiogenesis in 129SV wild-type mice is statistically similar to VEGF-induced angiogenesis.
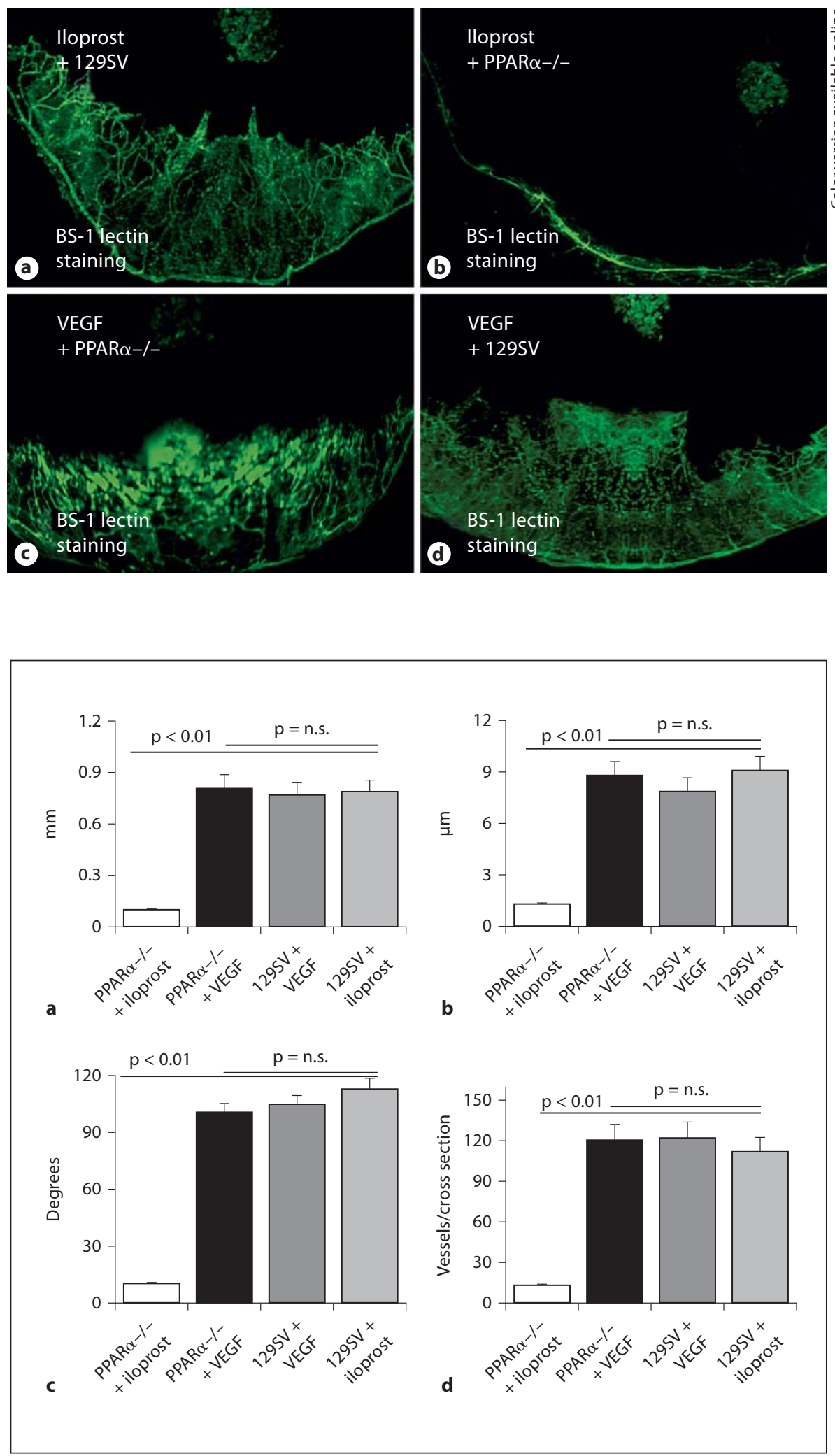
Fig. 3. Impaired iloprost-induced VEGF upregulation in PPAR $\alpha-/-$ mice. a Immunohistochemical analyses showing VEGFpositive staining in corneas of $129 \mathrm{SV}$ wildtype mice treated with iloprost. b No VEGF-positive staining is detectable in the corneas of PPAR $\alpha-/-$ mice treated with iloprost. c Negative control staining prepared by substituting preimmune rat serum. d Quantitative RT-PCR showing that iloprost induces upregulation of VEGF mRNA in the corneas of 129SV wild-type mice, but not in the corneas of PPAR $\alpha-/$ - mice. e ELISA showing that iloprost increases VEGF protein levels in the corneas of $129 \mathrm{SV}$ wild-type mice, but not in the corneas of PPAR $\alpha-/-$ mice.
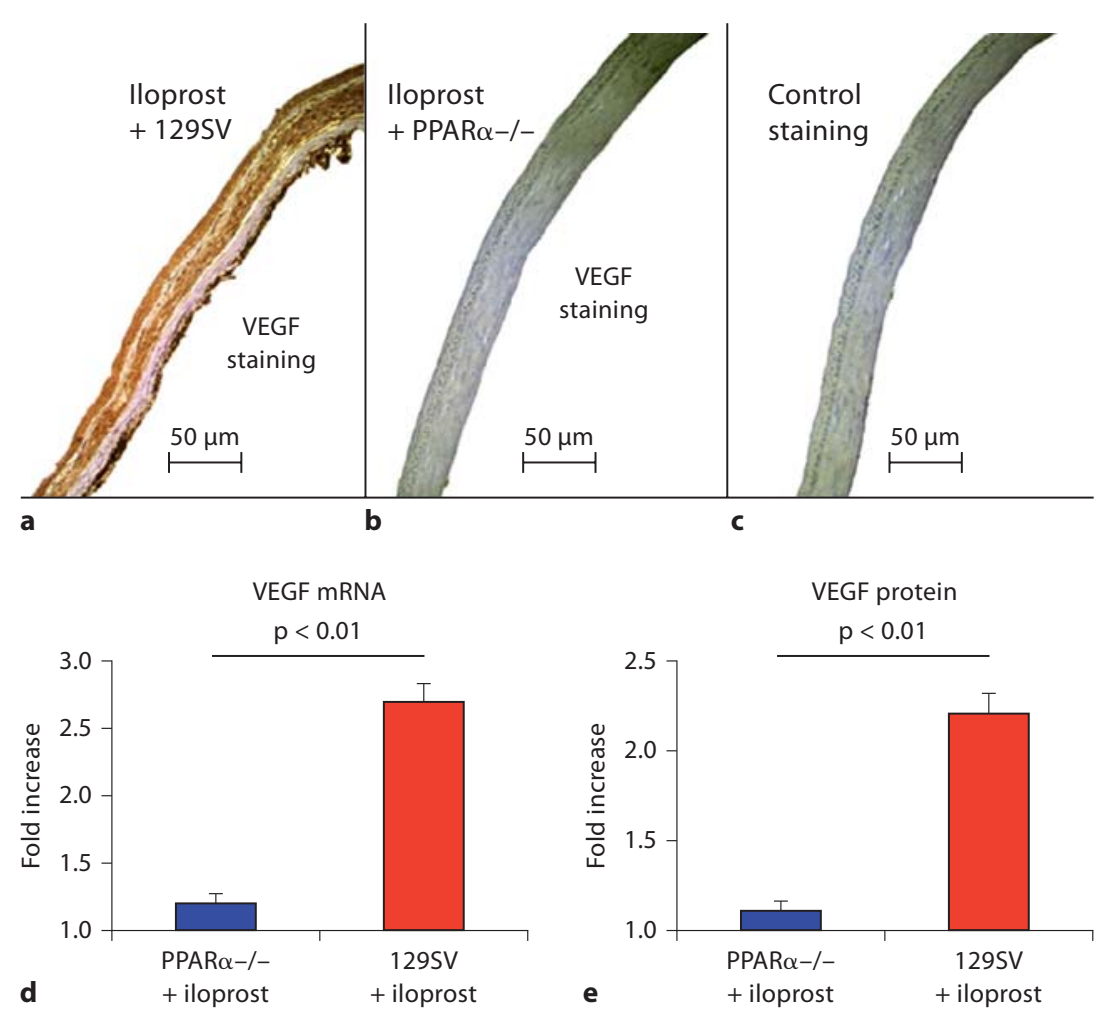

observed in corneas treated with pellets containing control buffer.

The extent of iloprost and VEGF-induced corneal neoangiogenesis was quantified in terms of vessel length, circumferential extent of neovascularity, number of vessels per cross section, and lumen diameter. These analyses demonstrated that, in wild-type mice, the morphological characteristics of the angiogenic response induced by iloprost and VEGF were statistically similar (fig. 2ad). In addition, VEGF-induced corneal angiogenesis did not differ, in terms of morphological characteristics, between wild-type and PPAR $\alpha-/-$ mice (fig. 2a-d).

We have previously demonstrated that iloprost induces angiogenesis through a VEGF-dependent mechanism. In this study, we tested the hypothesis that iloprost-induced VEGF upregulation could be impaired in PPAR $\alpha-/-$ mice. We found that no VEGF-positive immunostaining can be detected in the corneas of PPAR $\alpha-/-$ mice treated with iloprost, while positive VEGF staining is observed in the corneas of wild-type mice treated with iloprost (fig. 3a-c). We also analyzed the levels of VEGF mRNA and protein in iloprost-treated corneas of
PPAR $\alpha-/-$ mice and their wild-type littermates. Competitive RT-PCR showed that, while VEGF mRNA is strongly upregulated during angiogenesis induced by iloprost in wild-type mice, no VEGF upregulation occurs in the corneas of PPAR $\alpha-/$ - mice treated with iloprost (fig. 3d). Similar results were found in terms of VEGF protein levels (fig. 3e). These data suggest that the inability of iloprost to induce angiogenesis in PPAR $\alpha-/-$ mice depends on the fact that this $\mathrm{PGI}_{2}$ analogue is unable to stimulate VEGF activation in the absence of PPAR $\alpha$.

To further demonstrate that VEGF is crucial for iloprost-induced angiogenesis, pellets containing iloprost were implanted in the cornea of mice previously transfected with a gene encoding for the soluble form of the VEGF receptor Flt-1. This transfection results in systemic inhibition of VEGF activity $[4,8]$. A dramatic reduction of iloprost-induced angiogenic response was observed upon suppression of VEGF activity (fig. 4a, b). Iloprost-induced angiogenesis was significantly reduced in terms of vessel length, circumferential extent of neovascularity, and number of vessels per cross section (fig. 4c). 

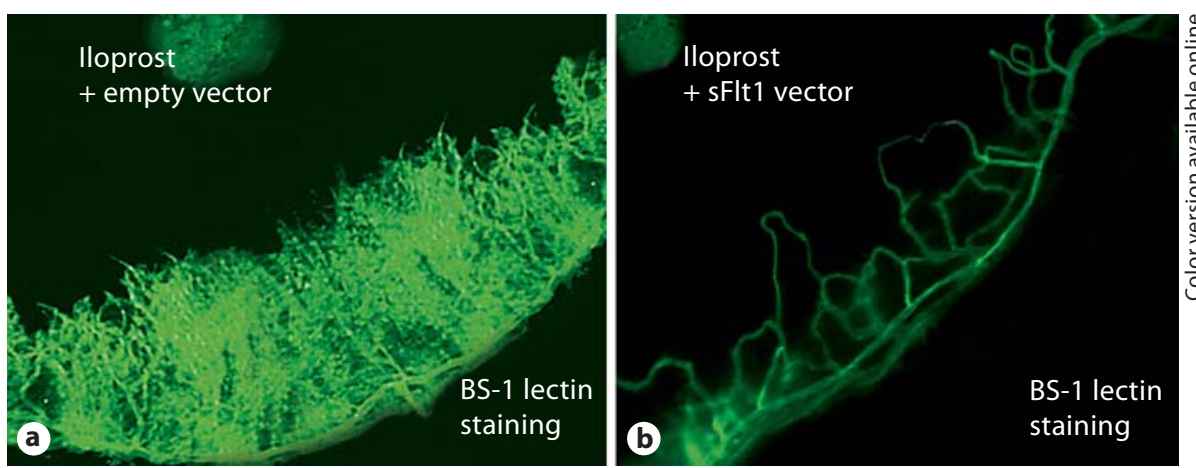

Fig. 4. Role of VEGF in iloprost-induced angiogenesis. a, b Inhibition of VEGF activity reduces the ability of iloprost to induce angiogenesis in the corneas of 129SV wild-type mice. c Quantification of iloprost-induced angiogenesis in the corneas of mice treated or untreated with sFlt1 vector to inhibit VEGF activity.

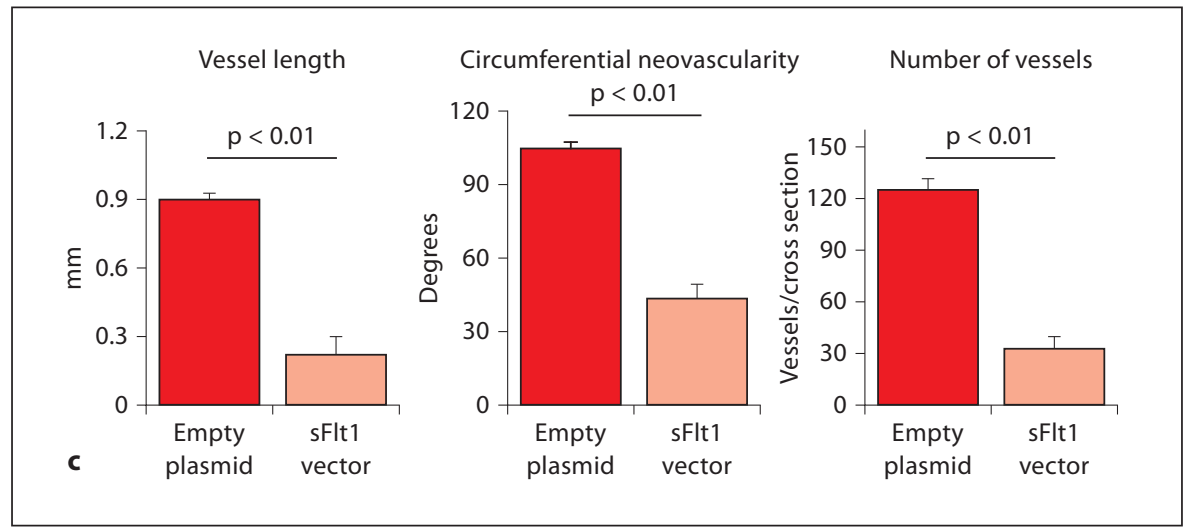

\section{Discussion}

In recent years, there has been increasing appreciation of the interdependent relationship existing between the $\mathrm{PGI}_{2}$ system and angiogenesis. On one hand, it is well known that $\mathrm{PGI}_{2}$ mediates several activities of VEGF and is considered one key molecule in linking postreceptor signaling networks to downstream biological effects of VEGF [9]. On the other hand, it has been reported that $\mathrm{PGI}_{2}$ may induce angiogenesis through production of VEGF, promotion of vascular sprouting, migration, and tube formation, and enhanced endothelial cell survival via $\mathrm{Bcl}-2$ expression and Akt signaling [10]. However, it is not clear whether the angiogenic effects of $\mathrm{PGI}_{2}$ occur via its classical interaction with IP surface receptors or activation of nuclear PPARs. Our study shows that the stable $\mathrm{PGI}_{2}$ analogue iloprost stimulates angiogenesis and upregulates VEGF in vivo through a PPAR $\alpha$-dependent mechanism, providing clear evidence of a functionally important intersection between the $\mathrm{PGI}_{2}$ system and the PPAR signaling pathway.

PPAR $\alpha-/-$ mice have been extensively studied in the literature and several anatomical, and functional defects have been reported in these mice, ranging from decreased glycogen levels and hypoglycemia to structural altera- tions of heart, liver, and skin [11-13]. However, this is the first demonstration that the absence of the PPAR $\alpha$ gene results in alterations of angiogenesis. It is important to point out that PPAR $\alpha-/-$ mice were able to mount an appropriate angiogenic process when stimulated with the prototypical angiogenic agent VEGF, thus indicating that angiogenesis is not endogenously compromised in these animals. Instead, a deficient angiogenic response and impaired VEGF upregulation were observed in PPAR $\alpha-/-$ mice upon stimulation with iloprost, thus suggesting that PPAR $\alpha$ is specifically involved in the molecular mechanisms responsible for $\mathrm{PGI}_{2}$-induced angiogenesis.

The PPAR $\alpha-/-$ mice used in this study have a 129 SV background. It is interesting to note that 129SV wild-type mice responded to iloprost and VEGF corneal stimulation by mounting an angiogenic response whose morphological characteristics were very similar to those displayed by C57BL/6J mice in a previous report by our group [4]. This finding indicates that, although animals from different strains might display different angiogenic abilities, the background of the animals used in these studies does not influence the angiogenic properties of the investigated molecules.

The corneal model is widely used in the field of angiogenesis to test the ability of a given molecule to stimulate 
and/or inhibit in vivo neovascularization. Although this model is not clinically significant, our data may have important clinical and therapeutic implications. Indeed, iloprost is commonly used for the treatment of several pathologic conditions, such as pulmonary hypertension, Raynaud's phenomenon, and critical limb ischemia. Our findings confirm the ability of iloprost to induce angiogenesis and VEGF upregulation in vivo and are consistent with those provided by other authors, who have recently demonstrated the ability of iloprost to stimulate angiogenesis in an experimental model of flow-associated pulmonary hypertension [14] and in a case of Raynaud's phenomenon associated with positivity for antinuclear antibodies [15]. Also the PPAR $\alpha$ signaling pathway is clinically relevant, as activators of this nuclear receptor are widely used to reduce the plasma levels of triglycerides and free fatty acids and to increase highdensity lipoproteins-cholesterol [16]. This study identifies regulation of iloprost-induced angiogenesis as a novel biological activity of PPAR $\alpha$ and provides new insights to understand the functional, clinical, and therapeutic properties of this nuclear receptor. Further studies using clinically relevant animal models of human diseases are needed to better understand the importance of these pathways in human pathology.
The PPAR $\alpha$ gene is affected by common single nucleotide polymorphisms. These gene variations have been associated with several pathologic conditions, including type 2 diabetes, metabolic syndrome, and atherosclerotic cardiovascular diseases. If PPAR $\alpha$ mediates certain biological properties of iloprost, then it is possible to hypothesize that functional polymorphisms of the PPAR $\alpha$ gene might influence the endogenous vascular activities of $\mathrm{PGI}_{2}$ and/or the individual response to treatment with $\mathrm{PGI}_{2}$ analogues. In this respect, it is intriguing to note that, in terms of clinical efficacy, subjects treated with iloprost can be classified as 'responders' and 'nonresponders' to treatment [17]. Based on our findings, it would be interesting to evaluate whether this difference might depend on the presence of specific PPAR $\alpha$ genotypes that are associated with a different level of function and/or expression of the PPAR $\alpha$ gene.

In conclusion, this study demonstrates that iloprost ability to induce angiogenesis in vivo depends on the presence and proper function of the PPAR $\alpha$ gene. The intersection between the $\mathrm{PGI}_{2}$ system and the PPAR signaling pathway merits further investigation for its potentially important biological, clinical, and therapeutic implications.

\section{References}

1 Hsu HH, Rubin LJ: Iloprost inhalation solution for the treatment of pulmonary arterial hypertension. Expert Opin Pharmacother 2005;6:1921-1930.

2 Pope J, Fenlon D, Thompson A, Shea B, Furst D, Wells G, et al: Iloprost and cisaprost for Raynaud's phenomenon in progressive systemic sclerosis. Cochrane Database Syst Rev 2000;2:CD000953.

3 Poggesi L, Comeglio M: The role of iloprost in the treatment of critical ischemia of the limbs (in Italian). Ann Ital Med Int 1993; 8(suppl):71S-77S.

-4 Pola R, Gaetani E, Flex A, Aprahamian TR, Bosch-Marce M, Losordo DW, et al: Comparative analysis of the in vivo angiogenic properties of stable prostacyclin analogs: a possible role for peroxisome proliferator-activated receptors. J Mol Cell Cardiol 2004;36:363-370.

5 Namba T, Oida H, Sugimoto Y, Kakizuka A, Negishi M, Ichikawa A, et al: cDNA cloning of a mouse prostacyclin receptor. Multiple signaling pathways and expression in thymic medulla. J Biol Chem 1994;269:9986-9992.

-6 Hertz R, Berman I, Keppler D, Bar-Tana J: Activation of gene transcription by prostacyclin analogues is mediated by the peroxisome-proliferators-activated receptor (PPAR). Eur J Biochem 1996;235:242-247.
7 Mangelsdorf DJ, Thummel C, Beato M, Herrlich P, Schutz G, Umesono K, et al: The nuclear receptor superfamily: the second decade. Cell 1995;83:835-839.

-8 Zhao Q, Egashira K, Inoue S, Usui M, Kitamoto S, Ni W, et al: Vascular endothelial growth factor is necessary in the development of arteriosclerosis by recruiting/activating monocytes in a rat model of long-term inhibition of nitric oxide synthesis. Circulation 2002;105:1110-1115.

-9 Zachary I, Gliki G: Signaling transduction mechanisms mediating biological actions of the vascular endothelial growth factor family. Cardiovasc Res 2001;49:568-581.

10 Gately S, Lee WW: Multiple roles of COX-2 in tumor angiogenesis: a target for antiangiogenic therapy. Semin Oncol 2004;31(2 suppl 7):2-11.

11 Djouadi F, Weinheimer CJ, Saffitz JE, Pitchford C, Bastin J, Gonzalez FJ, et al: A gender-related defect in lipid metabolism and glucose homeostasis in peroxisome proliferator-activated receptor alpha-deficient mice. J Clin Invest 1998;102:1083-1091.

-12 Lee SS, Pineau T, Drago J, Lee EJ, Owens JW, Kroetz DL, et al: Targeted disruption of the alpha isoform of the peroxisome proliferator-activated receptor gene in mice results in abolishment of the pleiotropic effects of peroxisome proliferators. Mol Cell Biol 1995; 15: 3012-3022.

13 Schmuth M, Schoonjans K, Yu QC, Fluhr JW, Crumrine D, Hachem JP, et al: Role of peroxisome proliferator-activated receptor alpha in epidermal development in utero. J Invest Dermatol 2002;119:1298-1303.

14 van Albada ME, Berger RM, Niggebrugge $\mathrm{M}$, van Veghel R, Cromme-Dijkhuis AH, Schoemaker RG: Prostacyclin therapy increases right ventricular capillarisation in a model for flow-associated pulmonary hypertension. Eur J Pharmacol 2006;549:107116.

15 Pyrpasopoulou A, Aslanidis S: Clinical images: iloprost-induced vascular remodeling. Arthritis Rheum 2007;56:2243.

- 16 Staels B, Dallongeville J, Auwerx J, Schoonjans K, Leitersdorf E, Fruchart JC: Mechanism of action of fibrates on lipid and lipoprotein metabolism. Circulation 1998; 98:2088-2093.

17 Opitz CF, Wensel R, Winkler J, Halank M, Bruch L, Kleber FX, et al: Clinical efficacy and survival with first-line inhaled iloprost therapy in patients with idiopathic pulmonary arterial hypertension. Eur Heart J 2005; 26:1895-1902. 